\title{
Jizo Bosatsu, Protetor das Crianças
}

\author{
Elton Vinicius Sadao Tada* \\ Verônica Regina Muller** \\ Vitor Chaves de Souza***
}

\begin{abstract}
RESUMO
O artigo resgata credos da tradição budista japonesa sobre Jizo Bosatsu, o protetor das crianças, a fim de interpretar, inicialmente, o lugar da infância na religião e na cultura japonesa. Para isso, o texto apresenta a origem e o conceito de Jizo Bosatsu, sua história e o nascimento da Terra Pura do Buda Amida como projeto salvífico de um dos ramos mais populares do budismo no Japão. Para entender o papel de Jizo Bosatsu, a pesquisa, portanto, utilizou o referencial filosófico de Paul Tillich a respeito da aproximação necessária entre religião e cultura enquanto chave hermenêutica para o tema. Conclui, ao final, que as crianças, enquanto seres sencientes, também possuem igual importância daqueles que já dominam a linguagem e a confissão religiosa, encontrando, assim, um lugar digno para a infância na sociedade.
\end{abstract}

Palavras-chave: Jizo Bosatsu; infância; budismo; salvação; Paul Tillich.

\section{Jizo Bosatsu, The Children Keeper}

\begin{abstract}
This paper works with Japanese Buddhist beliefs about Jizo Bosatsu, the protector of children, in order to interpret the childhood place in Japanese religion and culture. For this task, the paper presents Jizo Bosatsu's origin and concept, history and birth of the Pure Land of Buddha Amida as a salvific project for one of the most popular branches of Buddhism
\end{abstract}

* Teólogo. Mestre e Doutor em Ciências da Religião pela Universidade Metodista de São Paulo. Doutorando em Educação pela Universidade Estadual de Maringá. Realiza estágio pós-doutoral no PPG de Ciências da Religião da Universidade Metodista de São Paulo.

** Licenciatura em Educação Física pela Universidade Federal de Santa Maria. Mestrado em Educação pela PUC-RS. Doutorado e pós-doutorado em História da educação Social Contemporânea pela Universidad de Barcelona.

*** Doutor em Ciências da Religião. Professor no PPG de Ciências da Religião da Universidade Metodista de São Paulo. 
in Japan. To understand the role of Jizo Bosatsu, the research, therefore, appeal Paul Tillich's philosophical work regarding the necessary approximation between religion and culture as a hermeneutic key for this theme. It concludes that children, as sentient beings, also have equal importance to those who already dominate language and religious confession, thus finding a dignified place for childhood in society.

Key-words: Jizo Bosatsu; childhood; Buddhism; salvation; Paul Tillich.

\section{Introdução}

O presente artigo trata sobre o Jizo bosatsu no budismo japonês, seu conceito, sua história e sua função religiosa. Entretanto, o problema que se desenvolve ao longo do trabalho não é exclusivo sobre a figura de Jizo bosatsu, mas de sua relação com um conceito de infância, uma vez que o mesmo é cultuado popularmente como o bosatsu das crianças.

Primeiramente devemos situar a discussão na tradição japonesa para desdobrá-lo em uma reflexão hermenêutica acerca da religiosidade implícita na formação infantil. Bosatsu (菩薩) é o termo japonês para bodhisattva, termo em sânscrito que aparece tanto no budismo theravada quanto no budismo mahayana. No presente caso tratamos especificamente do budismo mahayana, com foco no budismo da Terra Pura japonês, levando, ainda assim, em conta a cultura religiosa do budismo chinês e japonês em geral. O bosatsu é um ser que está no caminho para tornar-se um Buda. Ainda não é um Buda no sentido estrito, pois não goza de plena iluminação; entretanto, possui uma mente iluminada e direciona sua existência para a iluminação de todos os seres sencientes ${ }^{1}$.

O bosatsu Jizo é um desses seres que caminha para a iluminação, para tornar-se um Buda, e em seu caminho possui diversas características que vão se desenvolvendo no universo da religiosidade budista. Atualmente, no budismo japonês sua figura está ligada à salvação de almas perdidas, ou seja, ele é invocado quando se pede para que a alma de alguém que faleceu seja encaminhada para a Terra Pura, ou simplesmente para que seja retirada de algum inferno. Além dessa função, Jizo Bosatsu também é invocado para ajudar as crianças que falecem

1 Termo no budismo para distinguir os seres que se direciona para o despertar. Para mais informações, consultar: BUSWELL, Robert E., LOPEZ, Donald S.. The Princeton Dictionary of Buddhism. Princeton: Princeton University Press, 2013. 
a encontrar o caminho no pós-vida, para abençoar crianças e mesmo mulheres que pretendem engravidar.

No artigo trataremos, portanto, especificamente da relação entre Jizo Bosatsu e as crianças, buscando a ideia de infância que se desenvolve no processo da relação infantil com a tradição japonesa, imbuída de religiosidade e sabedoria milenar.

\section{Jizo Bosatsu: origem e conceito}

Para uma compreensão adequada da amplitude cultural da discussão sobre a crença em Jizo bosatsu, faz-se importante o entendimento do pano de fundo no qual o budismo se desenvolveu: referimo-nos, basicamente, no contexto da rota da seda, expandindo-se das fronteiras da índia, alcançando o leste, moldando-se de acordo com a receptividade de cada cultura e sociedade alcançada pela religião. Elementos como política e geografia interferem nesse processo significativa e amplamente, gerando, como esperado, diferenças capitais no budismo do século XXI nas mais diversas partes do mundo. Deste modo, as formas de culto e crença no Jizo bosatsu também não são as mesmas, haja vista terem se desenvolvido historicamente em contextos plurais.

Dykstra, em seu artigo de 1978, apresenta, de forma geral, o desenvolvimento do culto a Jizo Bosatsu na literatura budista. Suas principais fontes datam de traduções chinesas de mais de doze séculos, principalmente o Ta-ch'eng-ta-chi-ti ts'ang-shih-lun-ching (em japonês, Juringyo) e o Ti-ts'ang-p'u-sa-pen-yuan-ching (em japonês, Hongankyo).

Como uma extensão desse conceito, o Juringyo introduz Jizo como aquele que aparece durante o longo período entre a morte do Buda Shakyamuni e a chegada de Maitreya, ou Miroku, o Buda futuro. As funcionalidades de Jizo são mais efetivas no período da lei degenerada, ou Mappô. O Juringyo afirma que ele é dotado de poderes misteriosos e que aparece do sul. Ele assume várias formas, incluindo o de discípulo ${ }^{2}$, monge, ou mesmo de Yen Lo Wang - Emma-o, em japonês - o juiz do inferno, para que assim possa ajudar a quem lá se encontra (DYKSTRA, 1978, p. 180).

2 O autor usa o termo sânscrito Śāvaka no texto original em inglês para indicar a figura do discípulo. 
O período chamado de Era da Lei Degenerada é interpretado por diversas traduções budistas como o período atual da humanidade. Em japonês, esse período é conhecido como Mappô, que seria, em termos mais práticos, a Era do Fim do Dharma. A saber, em tal período, no qual não há nenhum Buda ensinando diretamente a humanidade, a ajuda de bosatsus como Jizo é considerada muito adequada, pois aumenta o horizonte de atuação do Dharma na realidade na vida das pessoas que vivem em seus contextos cotidianos, não necessariamente próximas aos ensinamentos do Buda.

Sobre a entrada da figura do bosatsu Jizo no Japão, Dykstra aponta que:

De acordo com uma lenda antiga, a primeira estátua de Jizo foi trazida para o Japão no reinado do imperador Shômu e foi colocado primeiramente em Tachibanadera e depois no Hôryû-ji. Além das lendas e da tradição oral sobre Jizo, sabemos que monges japoneses e acadêmicos tinham familiaridade com este bodhisattva desde tempos remotos, já que numerosos sutras relacionados eram copiados durante o período Nara. Esses sutras incluem o Ching-kang-san-mei-ching, o Chan-ch'a-shan-e-yeh-pao-ching, o Ta-fang-kuang-shih-lun-chingt (copiado em 790), o Ta-ch'e'ng-ta-chi-ti-ts'ang-shih-lun-ching (copiado em 738-739), e o Ti-ts'ang-p'u-sa-ching (provavelmente o Hongankyo), copiado em 738 e 747. Depois, o Ti-ts'ang-p'u-sa-t'o-lo-ni-ching também parece ter sido copiado. Entretanto, escritos relacionados à crença nos dez reis e em Jizo, como o Yii-hsiu-shih-wang-sheng-ch'i-ching, não foram encontrados entre esses sutras copiados (DYKSTRA, 1978, p.180).

A entrada do bosatsu Jizo no Japão e o conhecimento de sutras a seu respeito mostra que a crença em tal bosatsu está presente na religiosidade japonesa há muitos séculos e se manteve até então.

Especificamente sobre a forma da crença em Jizo bosatsu, algumas narrativas colocam o bosatsu como um ser que intervém não apenas no pós-vida, mas no mundo presente, auxiliando os seres ignorantes a alcançarem a Terra Pura do Buda Amida.

Como repetidamente descrito nas histórias de Jizo do Reigenki e do Konjaku, Jizo também aparece nesta vida e ajuda seres sencientes ignorantes na era da degeneração. Ele guiaria seus devotos para que eles não caíssem no inferno e ele salvaria aqueles que já se encontravam no inferno. Essas características de Jizo como salvador são paralelas às de Kannon. O mérito do sutra de Lótus e o objetivo final desses dois bodhisattvas seria o de ajudar seus devotos a renascer na Terra Pura do Buda Amida (DYKSTRA, 1978, p.185). 


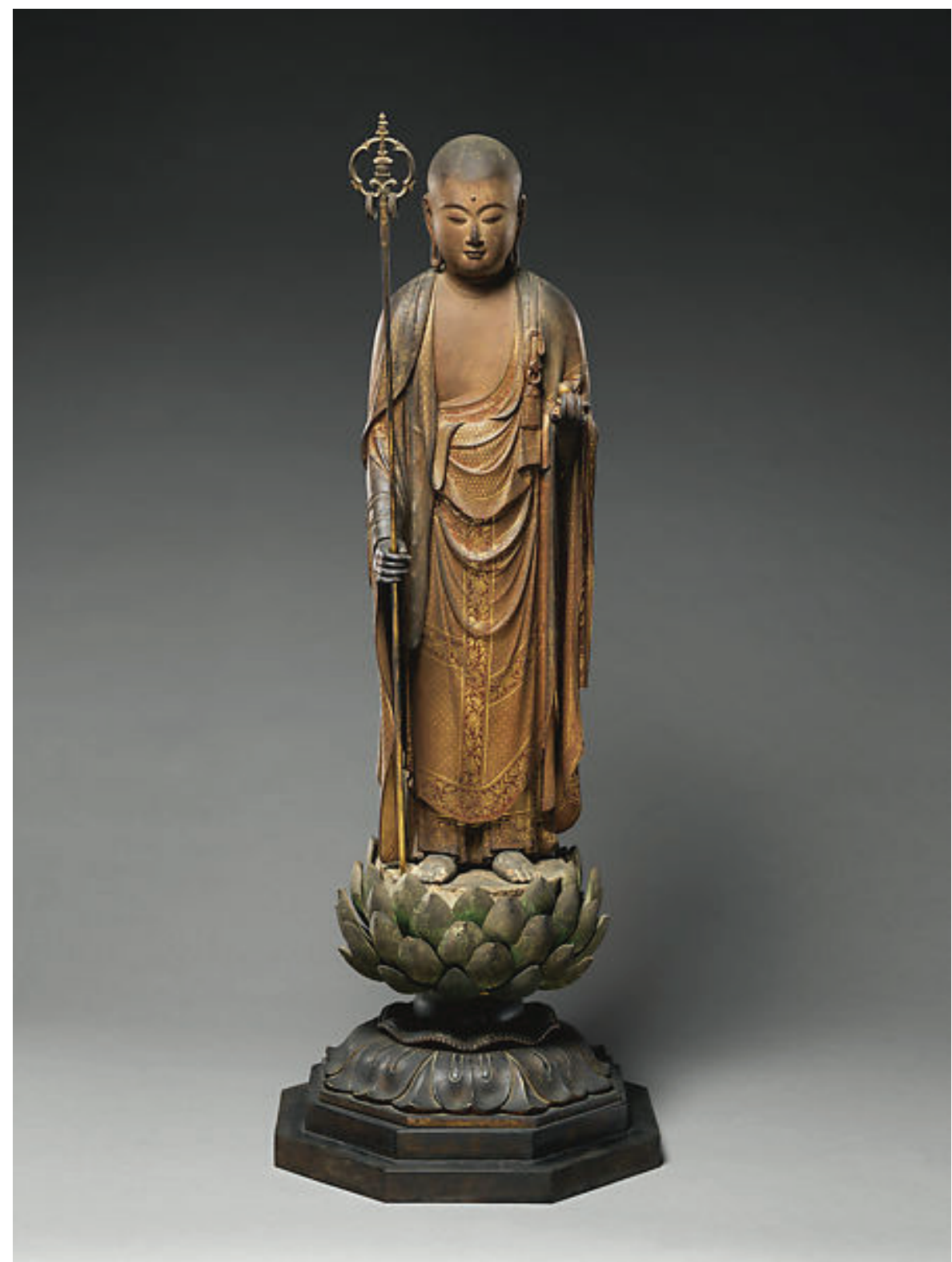

Figura 1 - Estátua de Jizo Bosatsu feita por Intan em 1291. Parte do acervo do Met museum em Nova Iorque. Disponível em: https://www.metmuseum.org/art/collection/search/76084 
O nascimento na Terra Pura do Buda Amida é o projeto salvífico de um dos ramos mais populares do budismo no Japão, o budismo da Terra Pura. Nesse sistema, os fiéis que não conseguiram atingir a iluminação nessa vida, por quaisquer motivos, seriam recebidos pelo Buda Amida em sua Terra Pura, enquanto seres sencientes, para apreenderem os ensinamentos diretamente do Buda e desenvolverem as práticas que possibilitariam a salvação final, a iluminação.

Segundo Dykstra, a salvação advinda da ajuda do bosatsu Jizo é ampla e incondicional.

Apesar de Amida e Jizo ambos salvarem até mesmo os maiores pecadores, a passagem acima revela uma distinção. Amida, especialmente do ponto de vista de Shinran, salvará qualquer um que recitar e repetir seu nome. Mas, Jizo não coloca condições para a salvação e salvará mesmo aqueles que não fizerem esforço algum para se relacionar com ele. Assim, os japoneses contemporâneos acreditam que Jizo os salvaria a qualquer momento, sem condições ou regras. Portanto, o bodhisattva representa a misericórdia suprema, e se qualquer um depositasse nele sua confiança, certamente seria salvo por meio de sua virtude e compaixão, sem nunca ter feito qualquer esforço para venerá-lo. Obviamente, este é um dos motivos pelos quais a crença em Jizo se tornou tão popular (DYKSTRA, 1978, p. 185).

Esse princípio mostra uma leve distinção entre a salvação proveniente do Buda Amida e do bosatsu Jizo. O Buda Amida condiciona sua salvação unicamente ao chamar de seu nome. Em seu voto central afirma que todo aquele que chamar pelo seu nome nascerá em sua Terra Pura após sua morte neste mundo. Jizo bosatsu, no entanto, salvaria também aqueles que não o buscaram. Justamente pela amplitude da salvação advinda da ajuda do bosatsu Jizo, sua figura ficou relacionada com a salvação das crianças - e exploraremos essa faceta da figura salvífica de crianças para investigarmos o lugar da figura sob uma reflexão cultural da religião.

\section{Jizo bosatsu e as crianças}

Os adultos podem confiar que ao recitarem o nome do Buda Amida renascerão em sua Terra Pura. Entretanto, algumas crianças podem morrer antes de conhecerem os ensinamentos de Buda e antes de terem 
chamado pelo nome do Buda Amida. Assim, as almas dessas crianças estariam desassistidas em seu caminho pelo pós-vida. Com base na ideia de misericórdia e compaixão sem fim de Jizo bosatsu é que se pede para que ele encaminhe as almas das crianças que morreram antes de conhecerem o dharma do Buda Amida.

O conceito do Jizo-criança se desenvolveu com base na crença de que Jizo protegeria as crianças, especialmente aquelas que morreram antes de ouvir os ensinamentos do Buda. Muitos contos folclóricos descrevem como Jizo protege as crianças dos demônios mensageiros do inferno. $\mathrm{O}$ famoso poema sobre Jizo e Sai no Kawara (Praia da margem do rio Sai), tocou profundamente as pessoas, especialmente aquelas que acabaram de perder suas crianças. (DYKSTRA, 1978, p.189)

Nesse trecho nota-se a importância da cultura popular, do folclore para a formação da religiosidade budista japonesa. Por mais que existam textos e sutras antigos que sirvam como base para as crenças budistas japonesas, há um refinamento que passa pela popularidade de assuntos específicos, como no caso da crença no bosatsu Jizo e em sua atuação a favor das crianças.

Não se torna difícil inferir que o refinamento do funcionamento da crença em Jizo bosatsu surge a partir de uma resposta a uma demanda específica. O fato de Jizo ser colocado como ajudador de todos, mesmo de quem nunca chamou pelo seu nome, permite que ele se encaixe em uma lacuna da crença no Buda Amida. A condição de salvação a partir do Buda Amida e de sua Terra Pura apresentada nos quarenta e oito votos, é a de que o sujeito chame, ao menos uma vez pelo seu nome.

Além de ser conhecido como o bosatsu que atende aos pedidos relacionados a crianças, Jizo bosatsu em sua multiformidade também se revela no formato de criança.

A manifestação de Jizo como criança pode ser resultado de uma visão xintoísta e folclórica das crianças. Há uma longa tradição, especialmente na história antiga do Japão, de que os deuses falam através das mulheres e das crianças. As mulheres xamânicas que atuavam como médiuns, bem como a ideia de que as crianças são seres misteriosos, forneceram um pano de fundo para esta tradição. Yanagita Kunio descobriu crenças nesse sentido no norte do Japão, onde se pensa eu uma criança, Zashiki Warashi (Criança na sala de estar) visita e é reconhecida por outras crianças, 
mas não é percebida pelos adultos. Grandes missionários e pregadores escolhem a forma de criança para Jizo como meio de popularização de seu culto, pois o coração das pessoas, carregado de amor pelas crianças, é tocado pela introdução dessa figura frágil e misteriosa. (DYKSTRA, 1978, p. 189).

A crença no Jizo bosatsu que se revela como criança está relacionada com crenças populares do xintoísmo, derivando, portanto, da religiosidade popular do Japão. Este elemento mostra como o culto a Jizo bosatsu se adequou de acordo com as realidades culturais dos locais nos quais o budismo se desenvolveu.

No Japão, a relação de Jizo bosatsu com as crianças é representada culturalmente a partir da tradição oral e do conhecimento popular. Uma das formas mais conhecidas de transmissão do conhecimento sobre a relação entre o bosatsu Jizo e as crianças é a lenda de Sai no Kawara:

Além de sua função no submundo, Jizo é considerado como o protetor das crianças, tanto vivas quanto mortas. Neste mundo, Jizo provê um bom parto, cura doenças de crianças, faz crianças pararem de chorar a noite, e assim por diante, enquanto que no submundo ele cuida de crianças que morreram cedo demais para prestar suas homenagens aos pais. De acordo com uma lenda muito conhecida, essas crianças estão presas nas margens do rio Sai (Sai no Kawara), e ficam empilhando pedras para acumular méritos para suas famílias. Toda noite demônios aparecem para derrubar as torres de pedras, momento no qual Jizo intervém, consolando as crianças. Na próxima manhã o ciclo infinito do empilhamento de pedras continua (DONNERE, 2019, p. 154).

O ciclo de trabalho contínuo de construção de torres de pedra é uma espécie de inferno no qual as crianças caem, por consequência kármica, de suas vidas. Nesse caso específico, as crianças que morrem muito cedo não têm a oportunidade de acumular méritos, gerando um karma que as leve para uma forma superior de existência. Por isso, tentam gerar esses méritos empilhando as pedras na margem do rio Sai. 


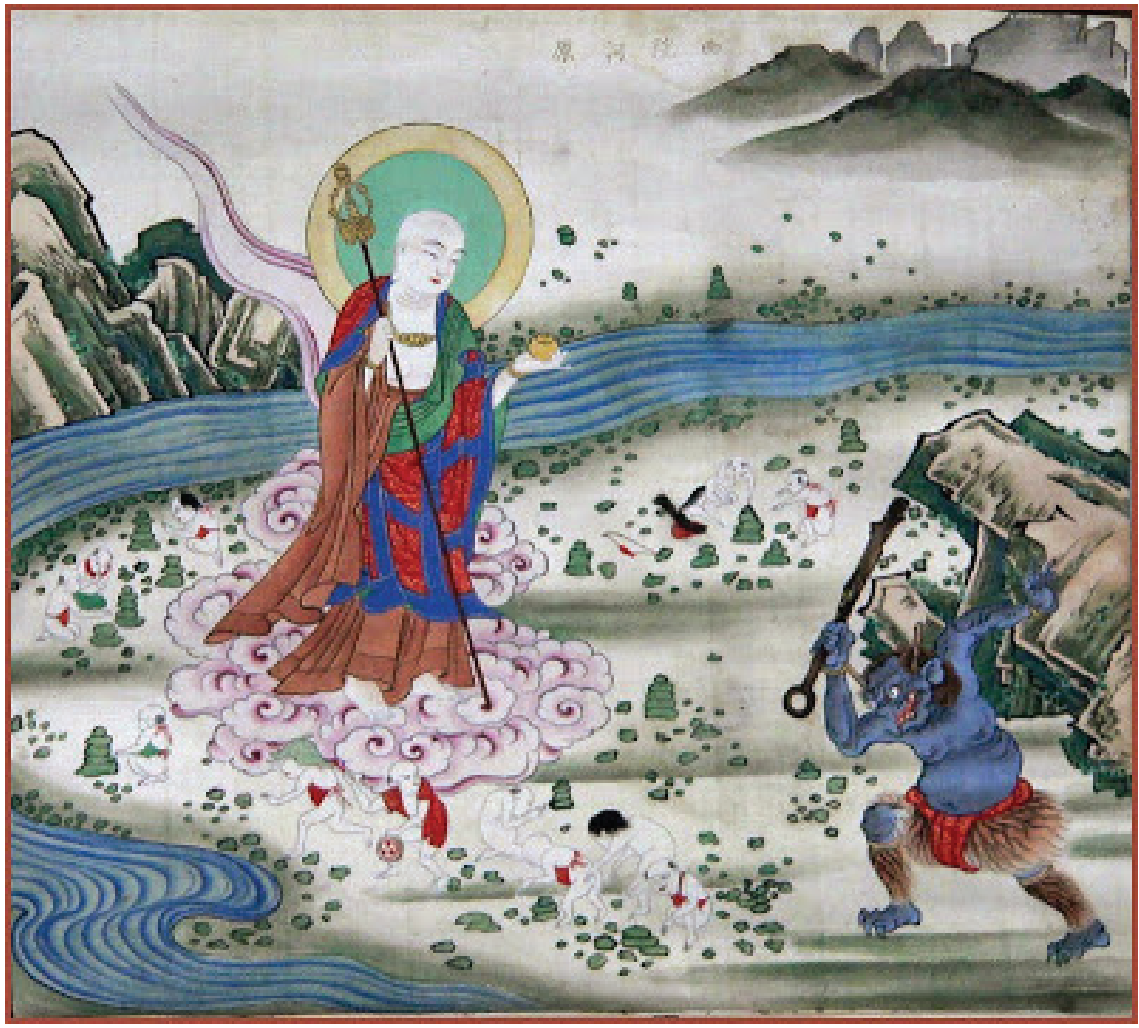

Figura 2 - Pintura de Jizo Bosatsu protegendo as crianças

nas margens do rio Sai. Disponível em: https://happyhaiku.blogspot.com/2004/12/jizoo.html

Com base nos contos da tradição japonesa, na tradição oral e na religiosidade popular, a figura de Jizo se torna cada vez mais relacionada com a proteção das crianças.

Na maioria dos casos, Mizuko Jizo pode ser facilmente reconhecido. A maioria das estátuas retrata Jizo com uma criança em suas mãos, às vezes cercado de outras pequenas crianças. Mizuko Jizo pode segurar cajados anelados e/ou jóias realizadoras de desejos, mas algumas delas não possuem qualquer dos atributos usuais de Jizo, a não ser pelo cabelo raspado e traje de monge. O outro tipo de Mizuko Jizo é uma pequena imagem infantil (cerca de 70 centímetros), normalmente fazendo Gasshô ou segurando um cajado anelado ou uma joia realizadora de desejos. Essas estátuas são majoritariamente erigidas como memoriais individuais e levam o nome da família ou o nome da criança falecida (DONNERE, 2019, p. 154). 
A imagem de Jizo passa pela forma de um monge budista, a princípio relacionado com o cuidado com as almas dos mortos sendo que em alguns casos é representado com uma criança no colo ou com crianças a seu redor chegando mesmo a ser representado com uma aparência infantil, no caso do Mizuko Jizo, representação atualmente muito popular de Jizo Bosatsu no Japão.

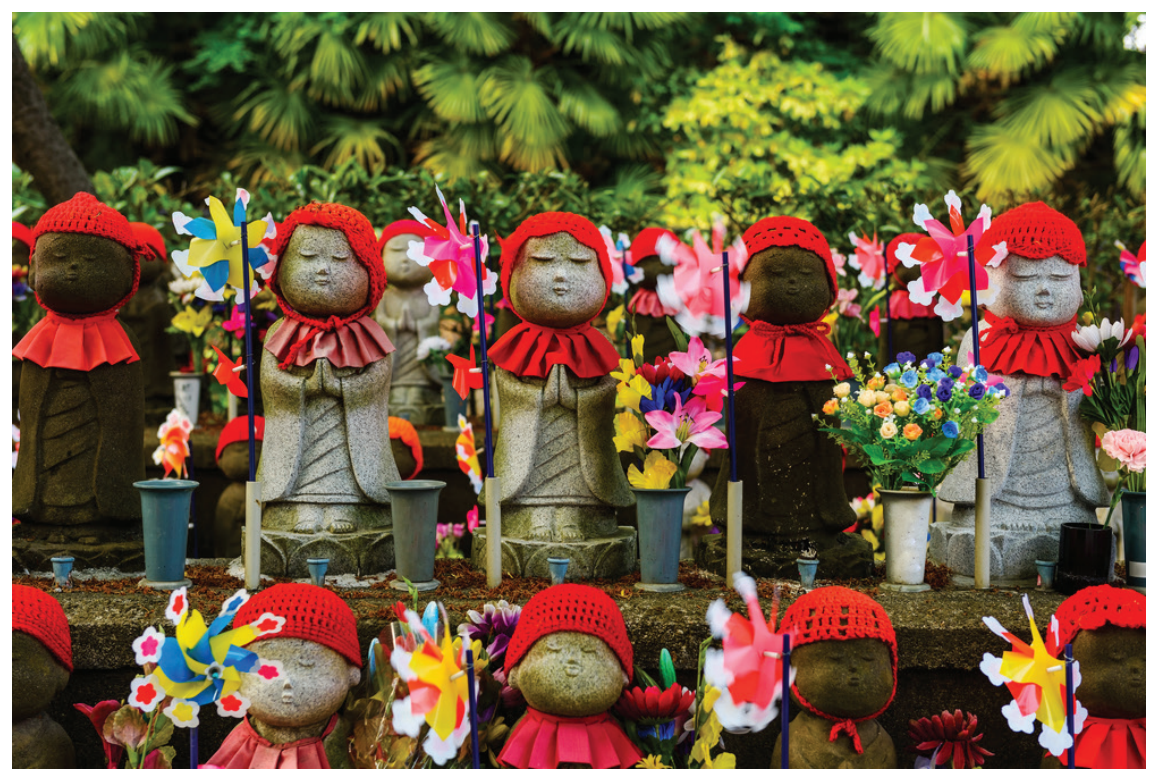

Figura 3: Diversas estátuas de Jizo Bosatsu no Templo Zojoji em Toquio. Disponível em: https://www.amusingplanet.com/2019/08/ mizuko-kuyo-japanese-ritual-of-mourning.html

A partir dessa apresentação sobre Jizo Bosatsu e de sua relação com as crianças, passaremos agora a uma abordagem hermenêutica da infância em relação ao Bosatsu Jizo.

\section{Uma aproximação hermenêutica da infância}

A configuração da imagem e do culto a Jizo Bosatsu no Japão, conforme previamente apresentado, nos dá alguns sinais que podem nortear nossa compreensão sobre qual é o pensamento sobre a infância que permeia a cultura budista japonesa e a cultura japonesa em geral. 
Paul Tillich, na terceira parte de sua Teologia Sistemática, faz um inventário de sua ideia de relação entre religião e cultura. No caso, ele afirma que existem três princípios para a relação entre religião e cultura.

O primeiro princípio encontramos na liberdade do Espírito. De acordo com ele, o problema de religião e cultura não é idêntico ao problema da relação entre as igrejas e a cultura. Poderíamos chamá-lo de "princípio da consagração do secular". Isto, porém, não significa que o secular como tal seja Espiritual, mas significa que ele está aberto ao impacto do Espírito e não necessita da mediação das igrejas (TILLICH, 2005, p. 689).

Esse princípio reflete bem como o culto ao Bosatsu Jizo se formou fora das estruturas da religião formal, sendo delineado através de contos populares e da tradição oral, atendendo a demandas específicas da sociedade ao longo dos tempos. Pela liberdade do Espírito a configuração do culto ao Bosatsu Jizo deslocou-se para a região paradoxal na qual a experiência religiosa depende - e, ao mesmo tempo, transcende - a mediação da instituição religiosa. Tal princípio reforça o culto budista, em sua estrutura formal, como uma demanda religiosa de um povo e uma época, fazendo-se presente a despeito dos condicionamentos de sua época.

O segundo princípio aponta que existe, necessariamente, uma relação convergente entre o sagrado e o secular, da qual podemos explicitar:

A tendência para esta convergência se explica pelo fato, já mencionado, de que o efeito latente da Presença Espiritual provém de e se dirige para uma manifestação dela numa comunidade histórica, numa igreja. [...] Nesse sentido, o secular é o corretivo necessário do sagrado. E, no entanto, ele próprio conduz ao sagrado [...] O secular é levado à união com o sagrado, uma união que na verdade é uma reunião, porque o sagrado e o secular pertencem um ao outro (TILLICH, 2005, p.689).

Este segundo princípio também se encaixa adequadamente com o processo de formação do culto de Jizo Bosatsu no Japão, uma vez que o movimento dependente do sagrado e do profano, enquanto traços da condição humana, faz-se presente na ambiguidade das relações. A religião formal acaba, por assim dizer, incorporando uma crença que surge na religiosidade popular e que se manifesta culturalmente através de lendas e construções folclóricas. Há uma imbricação quiasmática dos credos e crenças da cultura com a religião instauradora. Trata-se de 
uma materialização, às vezes paradoxal, das esferas sociais e culturais da religião vigente.

Há, por consequência, um terceiro princípio, que sintetiza os princípios anteriores, a saber:

Estes dois princípios estão enraizados num terceiro, o da "pertença essencial mútua de religião e cultura". Frequentemente expressei este princípio na afirmação de que a religião é a substância da cultura e a cultura é a forma da religião. Apontamos para ele quando analisamos a relação entre moralidade, cultura e religião. Aqui basta reafirmar que a religião não consegue se expressar sequer num silêncio significativo sem a cultura, pois todas as formas de expressão significativas provêm da cultura. E devemos reiterar que a cultura perde sua profundidade e inexauribilidade sem a ultimidade do incondicional (TILLICH, 2005, p. 691).

Tillich, na Teologia da Cultura, defende que religião e cultura se pertencem essencialmente e de forma mútua diante da dicotomia do condicionado. A cultura assume o papel de forma e a religião, de substância. Ambas são indissociáveis e devem, por tal indissociação, ser compreendidas em conjunto elementar. Nesse sentido, o olhar hermenêutico que se constrói na base tillichiana trabalha, assim concluímos, com um olhar relacional, sem tentar isolar um ou outro ponto dessa relação - que é, a rigor, um conjunto dialogal intrínseco em sua estrutura manifestada.

Assim, o olhar que se lança, aqui, sobre Jizo Bosatsu, seu culto e sua representação no Japão, é também um olhar relacional - ou, dialogal. A infância, como ponto focal, surge na seguinte estrutura: (1) o budismo é uma religião que se desenvolve em uma sociedade, no caso a sociedade japonesa; (2) essa sociedade elabora e expressa sua cultura, de modo que a religião influencia na cultura da sociedade assim como a cultura da sociedade influencia na religião; (3) Jizo Bosatsu, como o protetor das crianças, no budismo japonês e na cultura japonesa, refere-se a expressões dessa base relacional entre o cultural e o religioso.

Como vimos anteriormente, Jizo não é um bosatsu inicialmente voltado para a infância, mas foi direcionado para essa temática ao longo do desenvolvimento do budismo japonês. A marca de que essa adaptação surge de uma demanda social e é expressa pela cultura é que o fato de Jizo ser o protetor das crianças traça-se como uma linha transversal às 
diversas correntes e escolas budistas no Japão. Este não é um princípio que surge de uma doutrina ou de um patriarca específico, mas surge no cotidiano social e é adaptado nas diversas escolas de pensamento budistas. A não resistência a essa leitura de Jizo como o protetor das crianças no budismo japonês se deve ao caráter responsivo dessa crença a um problema social, que é inicialmente o problema do luto.

No budismo da Terra Pura, por exemplo, a salvação é condicionada a um elemento ativo exclusivo, o chamado ao nome do Buda Amida. Assim, a família enlutada que vê o ente querido partindo pode consolar-se na ideia de que a pessoa que chamou o nome do Buda Amida nascerá na Terra Pura (Ōjō 往生) e aprenderá o Dharma direto do Buda. A mesma lógica deixa a lacuna que é preenchida pela crença em Jizo Bosatsu como protetor das crianças. Se a salvação depende exclusivamente de um chamado ativo, qual seria, então, o destino das crianças que não chegaram a fazer tal ato? Aceitar que essas crianças estariam destinadas a alguma forma inferior de existência pela simples consequência kármica não seria o suficiente - nem para a religiosidade budista, nem para a sociedade japonesa.

Se a criança por si só não preencheu a condição para o nascimento na Terra Pura do Buda Amida, então sua família pode estender os méritos de suas práticas devocionais para que o Bosatsu Jizo acompanhe a ventura das crianças e assista para que suas existências sejam fortuitas. Cabe, agora, o exercício hermenêutico de fazer a mesma questão substituindo a linguagem religiosa pela linguagem filosófica. A preocupação está na substância religiosa e não no formato cultural, de modo que a cultura pode ser expressada tanto com linguagem religiosa quanto em linguagem filosófica, entre outras. Tillich, com seu engenho filosófico existencial, afirma que:

O homem cria o que ele é. Nada é dado a ele para determinar sua criatividade. A essência do seu ser o "deve ser", e o "tem que ser" — não é algo que ele encontre; ele o faz. O homem é o que ele faz de si próprio. E a coragem de ser como si próprio é a coragem de fazer de si próprio o que se quer ser (TILLICH, 1992, p. 114).

Numa direção parecida à de Feuerbarch - a ciência de Deus é a ciência de si mesmo -, os seres sensientes criam o que são para a 
relação de seu projeto interior. Seu ser não lhe é dado, mas feito com sua própria coragem e potência. A criança, especialmente aquela que ainda não domina a formalidade da linguagem, pode ser considerada como excluída dessa dinâmica, especialmente por não expressar algumas categorias filosóficas em sua linguagem (como, por exemplo, a não expressão da angústia, elemento sintomático em Kierkegaard) e não poder formular a expressão da consciência de seu próprio ser (consciência fundamental no Dasein heideggeriano). Kant, em outro momento, situa a fase infantil como a metáfora da passagem da minoridade para a maioridade filosófica. A despeito de tais preceitos e das limitações linguísticas e cognitivas da infância, o espaço da criança na tradição e religião japonesa é preservado na sabedoria budista para que, mesmo não ciente de sua projeção divina, a infância cultive a envergadura do ser na criação daquilo que ela é: o modo de ser criança.

Ainda assim, pensando a partir de outro prisma - o prisma de Jizo bosatsu -, a criança não seria a ausência de consciência de si mesma, mas a consciência mais próxima da completude na existência humana, dado a disposição para o início do despertar. A salvação de Jizo bosatsu se desvai de acordo com o domínio da linguagem, da presença cultural e das relações sociais, pois esses elementos criam as estruturas emocionais nas quais a consciência não apenas nota e afirma o ser do sujeito, mas o julga e o elabora como persona que constitui o si mesmo (até mesmo contrariando a condição universal e plural do modo de ser criança).

A linguagem filosófica não possui a preocupação com a salvação como a linguagem religiosa de Jizo bosatsu. Entretanto, o sentido e a finalidade do existir são problematizados tanto em um âmbito quanto no outro por conta da relação entre religião e cultura. A fragilidade da ideia de infância que perpassa a cultura japonesa e sua religiosidade pode ser compreendida com um olhar atento para o supracitado conto Sai no Kawara. A imagem das crianças na margem do rio Sai empilhando pedras para gerar méritos para si enquanto um ser externo desfaz o trabalho a cada noite, expressa o sentimento de que a criança não vai resolver sua situação por conta própria. Essa preocupação com o pós-morte é reflexo da preocupação com o pré-morte, de como a criança se comporta em vida. Portanto, pode-se ler daí, ainda que de modo sutil, que a sociedade japonesa lança essa responsabilidade para os pais em relação a seus filhos: 
a responsabilidade de não os deixar por conta própria nessa existência. Os seres sencientes, enquanto potência para o despertar, independente da idade, não são abandonados pela religião nem pela cultura japonesa, uma vez que o devir sobrepõe o acaso da existência.

\section{Considerações finais}

Neste artigo buscamos interpretar o lugar das crianças na relação entre religião e cultura japonesa. Mesmo que a filosofia ocidental coloque na criança uma semente do processo cognoscível, que lhe permitirá, no futuro, um alcance elevado e ideal, viu-se que, tratando-se da providência religiosa budista, a criança não é excluída de nenhuma camada social ou religiosa. A infância, como fase a ser abandonada na sociedade hoje, foi objeto de emancipações e liberdades, das quais procurou-se objetos e sentidos para o modo de ser criança, in-fans, infância, "ausência de voz". Se falta às crianças afeto e voz para apreenderem os ensinamentos diretamente do Buda e desenvolverem as práticas que possibilitariam a salvação final, em outras palavras, a iluminação, vimos que tal ausência não destina a fase infantil para um limbo de pensamento: ao contrário, a responsabilidade dos pais, mediada pela crença e confiança no bosatsu Jizo, possibilita uma reinserção não apenas religiosa, mas, principalmente, social, da criança. Ciente da relação necessária entre a forma da religião e a substância da cultura na formação da sociedade (que é religiosa), interpretar narrativas antigas, encontrando sabedorias nos textos milenares, faz-se uma prática hermenêutica rica para a compreensão de uma determinada religião, comunidade e, ao final, de nós mesmos que interpretamos, vivemos e nos despertamos.

\section{Referências bibliográficas}

BUSWELL, Robert E., LOPEZ, Donald S.. The Princeton Dictionary of Buddhism. Princeton: Princeton University Press, 2013.

DYKSTRA, Yoshiko Kurata. Jizō, the Most Merciful. Tales from Jizō Bosatsu Reigenki. In: Revista: Monumenta Nipponica, Summer, 1978, Vol. 33, No. 2 (Summer, 1978), pp. 179- 200.

DONNERE, Alise Eisho. "Finding a Place for Jizō: A Study of Jizō Statuary in the Buddhist Temples of Sendai". In: Japanese Journal of Religious Studies Vol. 46, No. 2 (2019), pp. 151-172 (22 pages) 
BAYS, Jan Chozen. Jizo Bodhisattva: Guardian of Children, Travelers, and Other Voyagers. Boston: Shambhala, 2002.

KOHAN, Walter. Infância. Entre Educação e Filosofia. Belo Horizonte: Autêntica, 2003.

LOUNDO, Dilip. "As Raízes Hinduístas do Budismo". In: Numen: revista de estudos e pesquisa da religião, v.20, n.1. Juiz de Fora: UFJF, 2017, pp. 47-56.

NARAIN, Harsh. The Madhyamika Mind. Delhi: Motilal Banarsidass Publishers, 1997.

WILSON, Jeff. Mourning the Unborn Dead: A Buddhist Ritual Comes to America. Oxford: Oxford, 2009.

TILLICH, Paul. A coragem de ser. Baseado nas Conferências Terry Pronunciadas na Yale University. Rio de Janeiro: Paz e Terra, 1992.

TILLICH, Paul. Teologia da cultura. São Paulo: Fonte editorial, 2009.

TILLICH, Paul. Teologia Sistemática. São Leopoldo: Sinodal, 2005.

USARKSI, Frank. O Budismo e as Outras: Encontros e Desencontros Entre as Grandes Religiões Mundiais. São Paulo: Editora Ideias e Letras, 2010.

WILLIAMS, Paul (Ed.). Buddhism: Critical Concepts in Religious Studies - Volume IV Abhidharma and Madhyamaka. New York: Routledge, 2005.

VERDU, Alfonso. The Philosophy of Buddhism. The Hague: Martinus Nijhoff Publishers, 1981. 